\title{
Inflammatory Bowel Diseases and Sarcopenia: The Role of Inflammation and Gut Microbiota in the Development of Muscle Failure
}

\author{
Olga Maria Nardone ${ }^{1 *}$, Roberto de Sire ${ }^{1}$, Valentina Petito ${ }^{2}$, Anna Testa $^{1}$, Guido Villani ${ }^{1}$, \\ Franco Scaldaferri ${ }^{2}$ and Fabiana Castiglione ${ }^{1}$ \\ ${ }^{1}$ Gastroenterology, Department of Clinical Medicine and Surgery, University Federico II of Naples, Naples, Italy, ${ }^{2}$ Department \\ of Medicine and Translational Surgery, Fondazione Policlinico Universitario "A. Gemelli" IRCCS, University Cattolica del Sacro \\ Cuore, Rome, Italy
}

OPEN ACCESS

Edited by: Monica Guma, University of California, San Diego, United States

Reviewed by:

Christelle Koechlin-Ramonatxo, Université de Montpellier, France

Chih-Yao Hou,

National Kaohsiung University of Science and Technology,

Taiwan

*Correspondence: Olga Maria Nardone olga.nardone@libero.it

Specialty section: This article was submitted to Autoimmune and Autoinflammatory Disorders, a section of the journal

Frontiers in Immunology

Received: 12 April 2021 Accepted: 28 June 2021 Published: 13 July 2021

Citation: Nardone OM, de Sire R, Petito V Testa A, Villani G, Scaldaferri F and Castiglione $F$ (2021) Inflammatory Bowel Diseases and Sarcopenia:

The Role of Inflammation and Gut Microbiota in the Development of Muscle Failure. Front. Immunol. 12:694217. doi: 10.3389/fimmu.2021.694217
Sarcopenia represents a major health burden in industrialized country by reducing substantially the quality of life. Indeed, it is characterized by a progressive and generalized loss of muscle mass and function, leading to an increased risk of adverse outcomes and hospitalizations. Several factors are involved in the pathogenesis of sarcopenia, such as aging, inflammation, mitochondrial dysfunction, and insulin resistance. Recently, it has been reported that more than one third of inflammatory bowel disease (IBD) patients suffered from sarcopenia. Notably, the role of gut microbiota $(G M)$ in developing muscle failure in IBD patient is a matter of increasing interest. It has been hypothesized that gut dysbiosis, that typically characterizes IBD, might alter the immune response and host metabolism, promoting a low-grade inflammation status able to up-regulate several molecular pathways related to sarcopenia. Therefore, we aim to describe the basis of IBD-related sarcopenia and provide the rationale for new potential therapeutic targets that may regulate the gut-muscle axis in IBD patients.

Keywords: IBD, sarcopenia, gut-muscle axis, gut microbiota, probiotics, inflammation, muscle wasting, malnutrition

\section{INTRODUCTION}

The European Working Group on Sarcopenia in Older People defined sarcopenia as a progressive and generalized skeletal muscle disorder, characterized by loss of muscle mass and function, low muscle strength and poor physical performance (1). Accordingly, it represents a major health burden in industrialized country by determining the risk of physical disability, poor quality of life, increased hospital admissions and increased mortality $(2,3)$.

Muscle impairment represents a common pathological hallmark of common chronic gastrointestinal diseases, including inflammatory bowel diseases (IBD). Recently, it has been reported that $42 \%$ of IBD patients suffered from sarcopenia (4). In addition, in most of them sarcopenia coexists with malnutrition as results of chronic inflammation.

Inflammatory bowel disease, including Crohn's disease (CD) and ulcerative colitis (UC), are chronic inflammatory disorders affecting the gastrointestinal tract, characterized by a relapsing- 
remitting course. Although their etiopathogenesis is still unknown, it has been hypothesized an aberrant immunemediated response to specific antigens of the gut microbiota (GM) in genetically predisposed individuals (5-9).

The GM represents a real ecosystem, consisted of more than $10^{14}$ bacteria and more than 1000 species as well as fungi, viruses, phages, parasites, and archea, that colonizes gastrointestinal tract and plays an important role in nutrient absorption, maintenance of metabolic homeostasis, protection from infections and development of systemic and mucosal immunity (10-13).

Several studies have shown significant difference in the GM composition between patients with IBD and healthy people. In particular, the phylum Firmicutes - specifically Faecalibacterium prausnitzii - is often reduced in the stool of patients with CD, while members of the Proteobacteria phylum, such as Enterobacteriaceae, including Escherichia coli, are commonly increased in patients with IBD compared to healthy individuals $(5,14-16)$. This contributes to a shift in the balance between commensal and potentially pathogenic microorganism that leads to dysbiosis (16).

Among several factors involved in the pathogenesis of sarcopenia, the role of GM in developing muscle wasting in IBD patients has now gained increasing interest. It has been hypothesized that GM moving from protective to proinflammatory effects, might alter the immune response and host metabolism, promoting a low-grade inflammation status able to up-regulate several molecular pathways related to sarcopenia, with consequent development of musculoskeletal impairment and frailty (17-19).

Therefore, this narrative review aims to describe the bases of IBD-related sarcopenia and to provide the rationale for new potential therapeutic targets that might regulate the gut-muscle axis in IBD patients.

\section{THE GUT-MUSCLE AXIS HYPOTHESIS}

Recently, growing data support the hypothesis of a "gut-muscle axis" $(5,20,21)$, wherein inflammation, gut dysbiosis, and malnutrition, interplay chorally for development of muscle failure in IBD patients (Figure 1). In this next section we focus on these key players of the gut-muscle axis.

\section{Inflammation}

The reduction of muscle mass and strength in sarcopenia increases with age. There are several factors involved in the development of muscle atrophy and age-related sarcopenia. The persistent low-grade inflammatory status in the elderly, characterized by increased circulating levels of proinflammatory cytokines, such as TNF-alpha, IL-6, and myostatin, defined as "inflammaging", is crucial (22-24). To date there were conflicting data with regards to the median ages of sarcopenic IBD patients. Zhang et al. reported that IBD patients with sarcopenia were significantly younger compared with those without sarcopenian (6), while according to Pedersen et al. sarcopenic patients were more likely to be older with more medical comorbidities, such as hypertension and diabetes, than younger non sarcopenic (25).

However, the intestinal inflammatory state that characterizes patients with IBD might be considered as the starting point for the development of muscle impoverishment, by activating several pathways in common with sarcopenia $(5,17,19)$.

TNF-alpha, produced by macrophages, lymphocytes, mast cells, fibroblasts and endothelial cells, is considered the key driver of intestinal damage, by stimulating macrophages to produce proinflammatory cytokines, inducing apoptosis of intestinal epithelial cells and Paneth cells, and stimulating the synthesis of proteases (26, 27). It is commonly believed that the disruption of intestinal epithelial tight junctions (TJ) leads to an increase of gut permeability with a consequent translocation of lipopolysaccharide (LPS) into systemic circulation. Several studies showed that the epithelial barrier function is impaired in IBD patients. Experimental models of colon biopsies of IBD patients hypothesized as a possible cause of barrier dysfunction a reduction of tight junction strands in both UC and CD (28-31). In response to the LPS stimuli, nuclear factor $\kappa B(\mathrm{NF}-\mathrm{kB})$ translocates from cytoplasm to nucleus and stimulates dendritic cells and macrophages to produce pro-inflammatory cytokines and mediators, for instance, cyclo-oxygenase-2 (COX-2), TNF-alpha, inducible nitric oxide synthase (iNOS), and IL-6, that regulate intestinal and systemic inflammation (28-31).

Importantly, it has been shown that increased serum levels of TNF-alpha are associated with muscle impairment. Indeed, TNF-alpha regulates the activation of NF-kB signaling pathway through the expression of the "atrogenes" (atrophy-related genes) and promotes protein degradation through the transcription of ubiquitin proteasome E3 ligases: muscle RING-finger protein-1 (MurF1), and Atrogin (32, 33).

In addition, IL- 6 produced by macrophages and T cells in the inflamed gut, is a pleiotropic cytokine able to upregulate the production of pro-inflammatory cytokines and inhibit $\mathrm{T}$ cell apoptosis through the activator of transcription 3 (STAT3) and hence contributes to the disruption of skeletal muscle proteosynthesis $(34,35)$.

Notably, the role of IL-6 in muscle homeostasis depends on the timing of its production. While during exercise IL- 6 transient production is associated with beneficial effects, a persistent elevation of its serum levels, in particular in elderly, is associated with muscle wasting and sarcopenia $(36,37)$. Of note, the reduced proteosynthesis and the increase in protein degradation of the skeletal muscle tissue seem to be promoted by the activation of three different cellular signaling pathways, all starting from the binding of IL- 6 and its receptor: the Janus kinasi (JAK)/STAT pathway, the Mitogen-activated protein kinase (MAPK)/Extracellular signal-regulated kinases (ERK) pathway and the Phosphoinositide 3-kinase (PI3K)/Protein kinase $\mathrm{B}(\mathrm{AKT}) / \mathrm{mammalian}$ target of rapamycin (mTOR) pathway (38).

In particular, the JAK/STAT signaling pathway is highly involved in IBD pathogenesis, mediating the function of several inflammatory cytokines implicated in gut inflammation, such as IL-2, IL-4, IL-6, IL-7, IL-9, IL-12, IL-15, IL-21, IL-23, and IFN-gamma (39). 


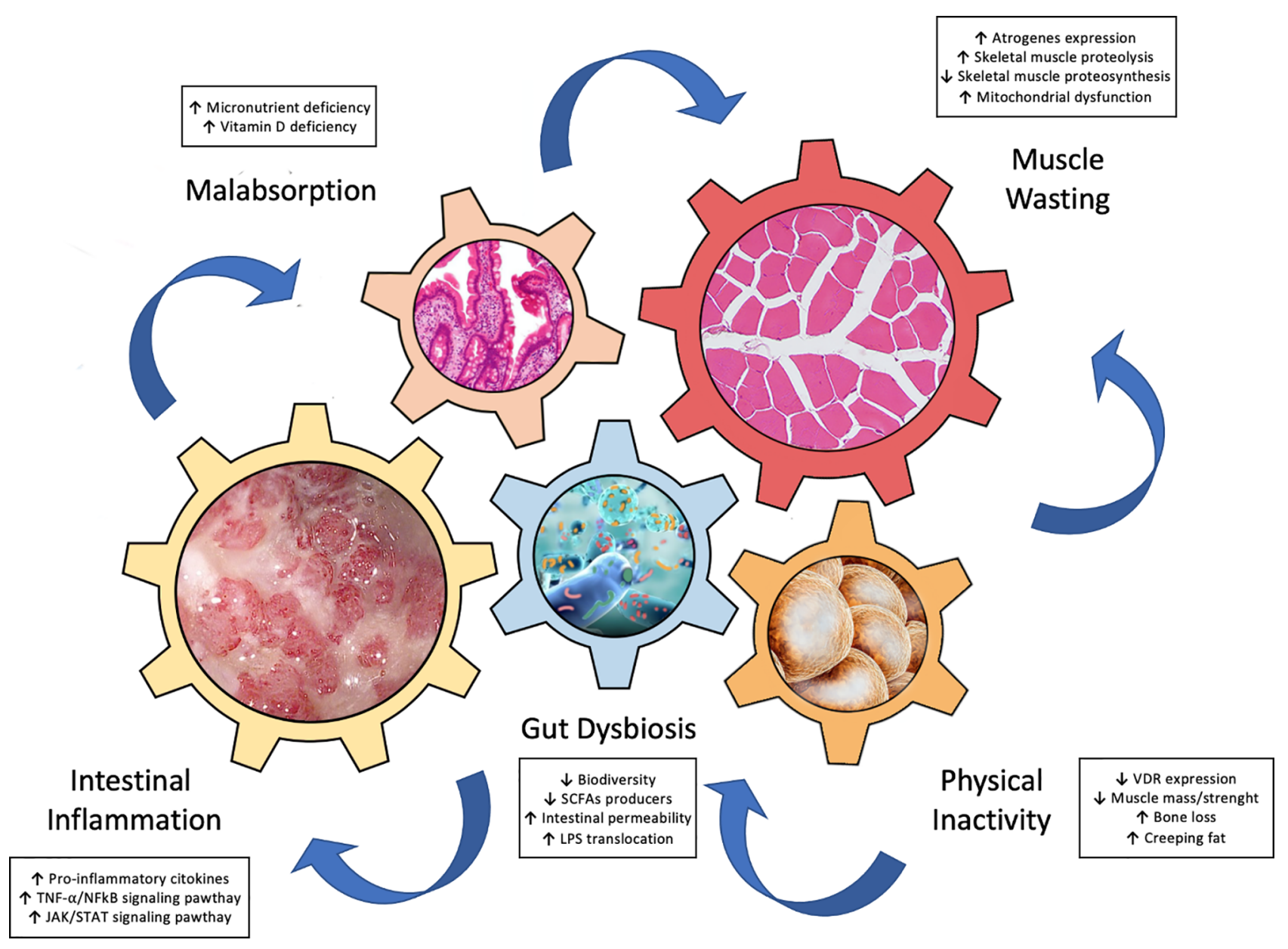

FIGURE 1 | Key drivers involved in the pathogenesis of "gut-muscle axis".

In this context, skeletal muscle fibers by expressing cytokine receptors and both the toll-like receptor (TLR)-2 and TLR-4 (which bind LPS), determine an overproduction of reactive oxygen species (ROS) and an oxidative stress (40). Given that mitochondria are the most vulnerable cellular organelle to ROS, the oxygen consumption decreases mitochondrial respiration and the ability to produce ATP. This process drives to disrupted mitochondrial dynamics and leads to "mitophagy", i.e. hyperactivation of mitochondrial degradation pathways (41).

In a number of chronic clinical disorders, such as also sepsis, heart failure and chronic obstructive pulmonary disease, mitochondrial dysfunction has been associated with increased systemic inflammation, which influences muscle protein synthesis and impairs both mitochondrial and muscle function (42). These processes are predominantly a consequence of oxidative stress secondary to ROS with a negative impact on skeletal muscle and hence are likely to contribute to the development of sarcopenia (42).

Although mitochondrial dysfunction has been founded in the intestinal epithelium of IBD patients, the role of epithelial mitochondrial stress in the pathogenesis of IBD has not yet fully understood (43). A recent study conducted by Jackson et al. identify Paneth cells as highly susceptible to mitochondrial dysfunction driven by loss of prohibitin 1 (PHB1), a major component protein of the inner mitochondrial membrane, and central to the pathogenesis of ileitis (44). This provides important translational implications for mitochondrial-targeted therapeutics in a subset of $\mathrm{CD}$ patients exhibiting Paneth cell defects (44).

Finally, there is a strict connection between mitochondria function and microbiota. In fact, the short chain fatty acids (SCFA) produced by gut bacteria is positively correlated with the expression of mitochondrial protein involved in the energy production, redox balance, and the modulation of the inflammatory cascade activation. However, in IBD patients, bacteria that ferment fibers and produce SCFAs are typically reduced in mucosa and feces as compared to healthy individuals. This low representation of SCFA producers in gut microbiota has been associated with increased subclinical chronic inflammation, which reinforces the skeletal muscle anabolic resistance (45). 


\section{Gut Dysbiosis}

Gastrointestinal tract and skeletal muscle tissue interact each other through a complex network modulated by the GM consisting of hormones, implicated in the homeostasis of energy metabolism, protein metabolism favors breakdown, and inflammatory mediators (i.e.TNF $\alpha$ ) which increase the permeability of the intestinal membrane and cause both local and systemic inflammatory effects $(18,20,21)$.

In IBD patients, this ecosystem is altered in terms of biodiversity, microbial composition and functions, determining the so-called "gut dysbiosis", that reflects an inappropriate immune response of a complex microbial community to the intestinal inflammation (46-48). It has been reported that IBD patients had a decrease of Firmicutes and Bacteroides, and a relative increase of bacterial species belonging to Enterobacteriaceae, that disrupt the intestinal barrier integrity, and an increase in mucolytic bacteria that determine the degradation of the mucosal barrier and thereby an increased penetration of pathogens into the intestinal tissues (49). This condition, defined as "leaky gut syndrome", represents a cofactor in the onset of a pro-inflammatory status leading to sarcopenia in both IBD and elderly patients $(50,51)$. Several studies showed an overall decrease in alpha and beta diversity of the gut microflora in IBD patients $(52,53)$. It has been reported by Qin et al. that in IBD patients' mucosal microbial genes are reduced of $25 \%$ compared to healthy controls (54). Recently, a comprehensive description of qualitative alterations in the gut microbiome of 132 patients affected by IBD has shown the presence of a functional dysbiosis in the gut microbiome during flairs of the disease with an increase in facultative anaerobes over obligate anaerobes, as well as molecular dysregulation in microbial transcription, metabolites, and serum levels of antibodies in the host (55). Particularly, Joossens et al. reported an increase in Ruminococcus gnavus and a decrease in Bifidobacterium adolescentis, Dialister invisus, Faecalibacterium prausnitzii, and an unknown member of Clostridium cluster XIVa in IBD patients (56).

However, GM influences resident mucosal immune cells to produce proinflammatory cytokines and microbiota-derived metabolites. Among them, SCFAs, secondary bile acids, watersoluble B-vitamins, tryptophan, polyphenols, and urolithins, are crucial for modulation of gut-muscle axis, by promoting insulin sensitivity, biosynthesis of amino acids, mitochondrial biogenesis, and muscular anabolism (21, 57-61).

Of note, several studies investigated the modulatory role of GM on the skeletal muscle functions and amino acid bioavailability (6264). For instance, in both frail and IBD population there is a decrease in Faecalibacterium prausnitzii, a SCFAs producer with a significant anti-inflammatory function. In addition, Bifidobacteria lactobacilli, involved in protein breakdown to amino acids within the gut, produce SCFAs for energy production, stimulate insulin growth factor -1 (IGF-1)/mTOR pathway and promote the expression of genes involved in muscle protein synthesis $(45,65$, 66). Similarly, Escherichia coli and Klebsiella play a role in the skeletal muscle anabolism and cell proliferation through the stimulation of the IGF-1/mTOR pathway (67).

Recently, Picca et al. profiled GM in older adults affected by physical frailty and sarcopenia, showing that an increase of
Oscillospira and Ruminococcus, and a decreased of Barnesiellaceae and Christensenellaceae microbial taxa, are associated with muscle impairment (68). Furthermore, it has been reported that exercise induces changes of GM with an important over-representation of some healthy bacterial species, such as Akkermansia, Prevotella, Faecalibacterium, and Roseburia, in fecal samples of humans with active lifestyle (69-73).

Regardless the correlation between GM and muscle function, Bjørkhaugh et al. showed that patients with chronic alcohol overconsumption had a loss of muscle strength, assessed by handgrip strength test, associated with a higher relative abundance of Proteobacteria, Sutterella, Clostridium and Holdemania and a lower relative abundance of Faecalibacterium with reduced SCFAs fecal levels (74). In a recent non-randomized trial examining the effect of exercise on GM modulation in 32 sedentary elderly women it has been reported that the abundance of Bacteroides was positively correlated with an increased physical performance assessed by the 6-min walking distance test (75). Furthermore Fielding et al. showed that the colonization of germ-free mice with GM of highfunctioning older adults is associated with an increase of muscle strength with a higher relative abundance of Prevotella and Barnesiella (76).

Therefore, the modulation of GM modulation could impact significantly on the onset of sarcopenia. Varian et al. have shown that the administration of Lactobacillus reuteri in mouse models of cancer could inhibit the development of sarcopenia and increase in muscle weight and fiber size, through an upregulation of the transcriptional factor Forkhead Box N1 (FoxN1) (77).

In a randomized controlled study prebiotic administration compared with placebo significantly improved two frailty criteria: exhaustion and increases the grip strength in elderly people over 65 years old (78). Similarly, Munukka et al. found that supplement of probiotics (Faecalibacterium prausnitzi) increased muscle mass that is linked to enhanced mitochondrial respiration, improved insulin sensitivity, modified gut microbiota composition and improved intestinal integrity (79).

Furthermore, folate and vitamin B12 are used as nutrient substrates by intestinal microflora for the maintenance of GM homeostasis; thus, nutrient deficiency negatively impacts on the GM function and consequently on muscle protein homeostasis (80).

\section{Malnutrition}

The chronic inflammation contributes to malnutrition through associated anorexia and decreased food intake; it further impacts on metabolism with elevation of resting energy expenditure and increased muscle catabolism (81). Of note, in more than two thirds of malnourished patients, sarcopenia coexists (82).

Malnutrition is also a condition that commonly affect IBD patients. In detail it has been reported in $65-75 \%$ of patients with CD and in $18-62 \%$ of patients with UC, as results of malabsorption, side effects of steroids, and increase in basal energy expenditure due to the inflammatory status (19). Importantly, malnutrition is typically associated to a significant alteration of body composition i.e. weight loss, reduction of 
skeletal muscle mass, bone loss, and expansion of visceral and "creeping" fat $(83,84)$.

The association of malnutrition and sarcopenia in IBD patients is controversial. Indeed, it is noteworthy that while malnutrition in IBD is characterized by weight loss during the acute phase of disease followed by a gradual recovery during disease remission, sarcopenia may be present even in IBD patients in remission and not only with low but also normal or elevated values of BMI (85-87).

However, the poor and/or inadequate oral intake is considered one of the most important determinants of IBDrelated malnutrition, due to a voluntary food restrictions and symptoms such as nausea, abdominal pain, vomiting, and diarrhea occurred in case of IBD flare up (88). Importantly, macronutrient intake is usually preserved in almost all IBD patients, while micronutrient deficiency, such as iron, copper, selenium, magnesium, zinc, vitamins and antioxidants, can occur more frequently (89). In addition, an insufficient protein intake can determine sarcopenia.

It is now clear that nutrients contribute significantly for the health of the trillions of bacteria, fungi, viruses, phages, parasites, and archea that compose the GM. Metagenomics analysis revealed that diet alters microbial community structure and overwhelms inter-individual differences in microbial gene expression (90-92). For instance, high-protein diets are associated with low microbial diversity. While a high-fat diet leads to a decrease in Bacteroidetes and an increase in Firmicutes, alterations that have been associated with an increase of opportunistic bacteria, intestinal permeability, low-grade systemic inflammation and insulin resistance (93). Conversely, promotion of insulin sensitivity, mitochondrial biogenesis, energy production and modulation of inflammation are induced by SCFAs produced by gut bacteria such as Faecalibacterium, Succinivibrio, and Butyricimonas (20). Of note, human studies focused on GM and malnutrition showed that children with protein energy wasting displayed an increase in Proteobacteria and a decrease in Bacteroidetes when compared with healthy children $(94,95)$.

Whilst there is a large body of supporting evidence for supplemental interventions for the prevention of muscle loss, strength and function in older adults, few data analyze this effect in patients with IBD.

Leucine supplementation, as well as vitamin D, in association with physical exercise increased skeletal muscle mass and muscle strength (96). Furthermore, the supplementation of betahydroxy-beta-methyl butyrate is associated with preservation of muscle tissue during short period of bed rest and increased muscle mass and strength, particularly in combination with resistance training (97-99).

Furthermore, vitamin D deficiency plays a key role in the onset of IBD-related sarcopenia (18). A recent metanalysis including 938 IBD patients, showed that lower vitamin D serum levels are more frequent in patients with IBD (64\%) than controls (100). Although the exact mechanism through which vitamin D affects skeletal muscle homeostasis is not totally elucidated, loss of muscle mass seems to be strictly related to the decrease of vitamin D receptor (VDR) expression (101). It has been reported that vitamin $\mathrm{D}$, once interacting with VDR, can elicit two different effects: 1) a non-genomic effect, such as modulation of calcium channel activation, muscle contraction and mitochondrial function; 2) a genomic effect, up-regulating nuclear expression of gene coding contractile proteins and myogenic transcription factors (102). It has been reported that VDR expression declines in elderly and in patients affected by chronic inflammatory diseases, such as IBD, chronic obstructive pulmonary disease, renal failure, diabetes and asthma $(103,104)$. Therefore, vitamin D serum levels should be monitored and supplemented to prevent the onset of osteoporosis and muscle wasting in IBD patients.

\section{STUDIES EXPLORING IBD AND SARCOPENIA}

\section{Animal Studies}

The exact pathogenesis of sarcopenia in IBD patients is still uncertain. Thus, in an attempt to elucidate the interaction between gut inflammation and muscle failure, experimental animal models were reproduced. These imply to collect gastrointestinal and muscle tissue samples, but also plasma and stools to assess serum markers of inflammation and perform microbiota analysis (21). The main mouse models of experimental IBD are induced by the intrarectal administration of trinitrobenzene sulphonic acid (TNBS), leading to a transmural colonic inflammation similar to that observed in CD patients, or through the oral intake of dextran sulphate sodium (DSS), promoting a histological intestinal inflammation similar to UC in humans (105).

It has been shown that skeletal muscle mass and proteins are reduced in murine models of TNBS-induced colitis, suggesting the linkage between IBD and muscle wasting (106). In this context, gut inflammation seems to be the trigger of skeletal muscle atrophy due to an accelerated rate of protein breakdown mediated by the up-regulation of the ubiquitin proteasome proteolytic pathway and enhanced expression of atrogin-1 and Murf-1 skeletal muscle atrophy-related genes (atrogenes) implicated in muscle protein breakdown (106).

Furthermore, a transcriptional upregulation of Murf-1, and consequent myofibril degradation was observed in mice affected by DSS-induced colitis. Indeed these latter differ from controls for the loss of skeletal muscle mass and decrease in muscle function, assessed by the significant reduction of the number of gastrocnemius myofibrils and the physical performance on rotarod test (107). Similarly, a mild chronic gut inflammation caused by DSS accelerates the muscle dysfunction evaluated by using rotarod test, gait analysis, and grip strength test in $\alpha$-synuclein mutant mice (108).

The analysis of molecular pathways of IBD-related sarcopenia assessed by using immunohistochemistry showed a downexpression of IGF1-R and Phospho-mTOR, markers of muscle growth, and an over-expression of Murf-1 and Myostatin, considered markers of sarcopenia (107). Similarly, Saul et al. 
showed that experimental IBD mice had a decrease in skeletal muscle weight and fiber size with a reduction of muscle protein content tested in quadriceps and gastrocnemius (109). Moreover, they observed an increased in mRNA expression of Murf-1 and Atrogin-1 suggesting an enhanced protein degradation responsible of sarcopenia (109).

However human muscle stem cells (hMuSCs) treated with IFN- $\gamma$ and TNF- $\alpha$ for 48 hours, and then transplanted intravenously, ameliorated colitis in mice treated with DSS by producing TNF-stimulated gene 6 (TSG-6) implicated in antiinflammatory functions (110).

Notably, animal models have been used also to evaluate the effects of gut microbiota manipulation on parameters of muscle mass and function. Indeed, probiotics seem to have a marked anti-inflammatory effect with beneficial consequences for muscle health through the promotion of anabolism. Probiotics containing Faecalibacterium prausnitzii, one of the main SCFA producers, were associated with improved liver anabolism and reduced systemic inflammation in mice models (79).

\section{Human Studies}

The assessment of nutritional status with body composition and an early detection of sarcopenia in patients with IBD is essential for providing an appropriate nutritional support, even during the remission period, and preventing sarcopenia-related surgical and negative outcome.

To date the majority of studies have defined sarcopenia as a loss of muscle mass. Typically, three imaging techniques have been employed for the assessment of muscle mass: computed tomography (CT), dual energy X-ray absorptiometry (DXA) and bioelectrical impedance analysis (BIA). While CT allows a direct estimate of muscle mass, DXA and BIA only provides indirect estimates such as lean mass. However, according to the revised European Working Group on Sarcopenia in Older People (EWGSOP), the definition of sarcopenia was also based on muscle function, quantity and physical performance (1). The muscle function is commonly evaluated through the handgrip strength, 5-times repeated chair stand test and 4-meter walking speed, while the physical performance can be measured by gait speed, the Short Physical Performance Battery, and the Timed-Up and Go test.

Ryan et al. performed a systematic review, including a total of 658 patients, to assess the prevalence of sarcopenia in IBD patients and the correlation between sarcopenia and needs of surgery and surgical outcomes in patients with IBD (4). Forty-two percent IBD patients had a diagnosis of sarcopenia detected with radiologic assessment of body mass composition and had an increased risk of requiring surgery with high rate of major complications after surgery (4).

Notably, sarcopenic IBD patients had lower preoperative serum levels of albumin and higher preoperative serum levels of C-reactive protein, deemed markers of malnutrition/ inflammation and predictive factor of surgical negative outcome (86). Furthermore, a recent cross-sectional study involving 344 IBD patients in clinical remission revealed an increased risk of sarcopenia in malnourished patients (87).

However, in addition to muscle wasting, two thirds of IBD population had a lower perception of muscle strength with an increased asthenia and a decreased quality of life, similarly to geriatric controls; importantly, the combination of the quantitative and the qualitative parameters of muscular disorder configured a condition of sarcopenia in $28 \%$ of IBD patients (19).

Recently, mesenteric fat proliferation is gaining growing attention. Indeed, many studies support the active role of mesenteric fat creeping in the pathophysiology and clinical course of CD. Grillot et al. described the association between sarcopenia and visceral obesity assessed by computed tomography (CT) with adverse outcomes in severe CD patients, supporting the hypothesis that the human fat is considered as a dynamic tissue involved in the immunity regulation and consequent inflammation response (111).

Interestingly, the visceral to subcutaneous adipose tissue area ratio has been considered as a biomarker of complications of CD, such as stricture and fistula (111).

Bamba et al. observed that the muscle volume and visceral adipose tissue volume (relative to subcutaneous adipose tissue volume) are associated with the long-term outcome of intestinal resection (112). In detail, it has been shown that male sex, $C D$, low psoas muscle index, and high visceral adipose tissue volume are associated with bowel surgery; therefore, moderate exercise and elemental diet might be useful for maintaining muscle mass and reduce visceral fat (112).

Biologic therapy, including anti-TNF alpha agents and newer anti-interleukin, anti-integrin, and JAK inhibitors agents used for treatment of IBD, might reduce sarcopenia, blocking the catabolic effects on skeletal muscle tissue (54). Nevertheless, there are only few studies investigating the potential role of biologics in the prevention of muscle wasting in IBD patients. Subramaniam et al., showed that in active $\mathrm{CD}$ the treatment with infliximab can reverse IBD-related sarcopenia, leading to a significant improvement in both skeletal muscle volume and maximal isokinetic strength after 6 months of therapy (113). These highlight the key role of NF-kB signaling pathway in development of muscle impairment (113). Similarly, it was observed an improvement of BMI and muscle parameters, described as fat free mass index, after 3 months of infliximab or adalimumab, suggesting the beneficial effect of the anti-TNF alpha therapy on the nutritional status and body composition of IBD patients (114) (Table 1).

With regards to the effects of gut microbiota interventions on parameters of muscle mass and function, most of the available studies were carried out on animal models as we mentioned before. Few data have explored the impact of manipulating gut microbiota on skeletal muscle outcomes in humans. A randomized controlled trial (RCT) explored the effects of a mixture of inulin and fructooligosaccharides (FOS) versus placebo in ambulatory elderly residing in nursing homes for 13 weeks. Of note, the intervention group experienced significant improvements in handgrip strength and self-reported feeling of exhaustion (78). Subsequently Theou et al. conducted secondary analysis by using a similar intervention (inulin+FOS versus placebo) and showed improvements in physical function, frailty degree, nutritional status and quality of life following a 12-week intervention in frail elderly (115).

Thus, these data support the hypothesis of a modulation of muscle function by gut microbiota. However, translation of these results in IBD patients is uncertain. A clinical application of the 
TABLE 1 | Principal human studies that explored the relationship between inflammatory bowel diseases and sarcopenia.

\begin{tabular}{|c|c|c|c|c|c|}
\hline $\begin{array}{l}\text { Authors, } \\
\text { Year }\end{array}$ & $\begin{array}{l}\text { Study } \\
\text { Design }\end{array}$ & $\begin{array}{l}\text { Study } \\
\text { Population/ } \\
\text { Number of } \\
\text { patients }\end{array}$ & Intervention/Groups & Outcomes & Key findings \\
\hline $\begin{array}{l}\text { Subramaniam } \\
\text { et al. (113), } \\
2015\end{array}$ & $\begin{array}{l}\text { Prospective } \\
\text { Study }\end{array}$ & $\begin{array}{l}99 \text { patients } \\
\text { with CD }\end{array}$ & $\begin{array}{l}\text { MRI volume of quadriceps femoris, } \\
\text { maximal concentric quadriceps } \\
\text { contractions strength, physical activity, } \\
\text { and serum levels of IL6 were assessed at } \\
\text { week } 1 \text { (pretreatment), week } 16 \text { (post-IFX } \\
\text { induction) and week } 25 \text { (post-first IFX } \\
\text { maintenance dose) }\end{array}$ & $\begin{array}{l}\text { Gain of muscle volume } \\
\text { and strength after anti- } \\
\text { TNF alpha therapy }\end{array}$ & $\begin{array}{l}\text { The anti-TNF agent infliximab reverses } \\
\text { inflammatory sarcopenia in patients with CD }\end{array}$ \\
\hline $\begin{array}{l}\text { Adams et al. } \\
\text { (86), } 2017\end{array}$ & $\begin{array}{l}\text { Retrospective } \\
\text { Study }\end{array}$ & $\begin{array}{l}90 \text { IBD } \\
\text { patients }\end{array}$ & $\begin{array}{l}\text { IBD patients starting a new anti-TNF alpha } \\
\text { therapy that had CT within } 3 \text { months of } \\
\text { initiation }\end{array}$ & $\begin{array}{l}\text { Hospitalization, need for } \\
\text { surgery, or new } \\
\text { biological medication }\end{array}$ & $\begin{array}{l}\text { 45\% of IBD patients were sarcopenic; of these, } \\
19.5 \% \text { were overweight/obese. CRP was higher } \\
\text { and albumin lower in sarcopenic subjects. } \\
\text { Sarcopenia was the only significant predictor of } \\
\text { need for surgery in overweight and obese } \\
\text { patients }\end{array}$ \\
\hline $\begin{array}{l}\text { Pizzoferrato } \\
\text { et al. (19), } \\
2019\end{array}$ & $\begin{array}{l}\text { Prospective } \\
\text { Study }\end{array}$ & $\begin{array}{l}127 \text { IBD } \\
\text { patients }\end{array}$ & $\begin{array}{l}\text { Four cohorts of patientswere recruited: } \\
\text { 1. IBD patients } \\
\text { 2. healthy controls } \\
\text { 3. healthy elderly } \\
\text { 4. elderly with primary sarcopenia }\end{array}$ & $\begin{array}{l}\text { Rate of sarcopenia in } \\
\text { IBD patients }\end{array}$ & $\begin{array}{l}36 \% \text { of patients with IBD showed a significant } \\
\text { reduction in skeletal muscle mass associated } \\
\text { with a lower perception of muscle strength with } \\
\text { a higher incidence of asthenia and reduction in } \\
\text { quality of life }\end{array}$ \\
\hline $\begin{array}{l}\text { Ryan et al. (4), } \\
2019\end{array}$ & $\begin{array}{l}\text { Systematic } \\
\text { Review }\end{array}$ & $\begin{array}{l}658 \text { IBD } \\
\text { patients }\end{array}$ & Five studies & $\begin{array}{l}\text { Needs of surgery and } \\
\text { surgical outcomes }\end{array}$ & $\begin{array}{l}42 \% \text { of IBD patients had sarcopenia. IBD } \\
\text { patients had a higher probability of requiring } \\
\text { surgery. The rate of major complications was } \\
\text { significantly higher in patients with sarcopenia }\end{array}$ \\
\hline $\begin{array}{l}\text { Grillot et al. } \\
(111), 2020\end{array}$ & $\begin{array}{l}\text { Retrospective } \\
\text { Study }\end{array}$ & $\begin{array}{l}88 \mathrm{CD} \\
\text { patients }\end{array}$ & $\begin{array}{l}\text { CD patients who had abdominal CT } \\
\text { scans during hospitalization }\end{array}$ & $\begin{array}{l}\text { Prevalence of sarcopenia } \\
\text { and visceral obesity in } \\
\text { CD patients and its } \\
\text { association with adverse } \\
\text { events }\end{array}$ & $\begin{array}{l}\text { The prevalence of sarcopenia was } 58 \% \text {. Among } \\
\text { sarcopenic patients, } 13.7 \% \text { were overweight, } \\
\text { and } 2 \% \text { were obese. Sarcopenic CD patients } \\
\text { had significantly more abscesses, } \\
\text { hospitalizations and surgery. Both sarcopenia } \\
\text { and visceral obesity were associated with } \\
\text { adverse outcomes }\end{array}$ \\
\hline $\begin{array}{l}\text { Bamba et al. } \\
\text { (112), } 2020\end{array}$ & $\begin{array}{l}\text { Prospective } \\
\text { Study }\end{array}$ & $\begin{array}{l}187 \text { IBD } \\
\text { patients }\end{array}$ & $\begin{array}{l}\text { IBD patients who were admitted to } \\
\text { hospital and underwent abdominal CT }\end{array}$ & $\begin{array}{l}\text { Association of skeletal } \\
\text { muscles and adipose } \\
\text { tissue measured at the } \\
\text { third lumbar vertebra } \\
\text { level on CT image with } \\
\text { clinical outcomes in IBD } \\
\text { patients }\end{array}$ & $\begin{array}{l}\text { Male sex, } C D \text {, low psoas muscle index, and high } \\
\text { visceral to subcutaneous adipose tissue area } \\
\text { ratio were associated with intestinal surgery }\end{array}$ \\
\hline $\begin{array}{l}\text { Ünal et al. } \\
(87), 2021\end{array}$ & $\begin{array}{l}\text { Cross- } \\
\text { sectional } \\
\text { Study }\end{array}$ & $\begin{array}{l}344 \text { patients } \\
\text { with IBD }\end{array}$ & IBD patients in clinical remission & $\begin{array}{l}\text { Nutritional status and } \\
\text { sarcopenia in patients } \\
\text { with IBD in clinical } \\
\text { remission }\end{array}$ & $\begin{array}{l}\text { Sarcopenia was diagnosed in } 41.3 \% \text { of patients. } \\
5.5 \% \text { of patients were underweight and } 9.9 \% \\
\text { were malnourished. Total number of flares } \\
\text { requiring hospitalization was the most important } \\
\text { predictor of sarcopenia }\end{array}$ \\
\hline
\end{tabular}

basic science background linking gut microbiota with sarcopenia should be the challenge of future innovative research in IBD population. Hence further studies are awaited.

\section{CONCLUSIONS}

The gut-muscle axis is a very promising area of research for the management of sarcopenia in IBD. It could be hypothesized that GM targeted treatment or complementary therapy such as physical activity and nutritional supplementation could be proposed to patients suffering from IBD and sarcopenia. Since sarcopenia has a negative impact on clinical outcome in IBD patients such as the need for surgical intervention and higher risk of post-operative complications, the assessment of muscle function and nutritional status should be adopted in the daily management of IBD patients. The modulation of the immune response, GM, oxidative stress, mitochondria disfunctions and metabolic processes could give potential benefits for IBD patients to improve muscle mass, muscle function and hence clinical outcomes. An incremental clinical benefit of blocking the catabolic effects on skeletal muscle tissue could be observed in IBD patients with sarcopenia treated by biologics including antiTNF alpha agents and newer anti-interleukin, anti-integrin, and JAK inhibitors agents used for treatment of IBD. However, the evidence for GM targeting in IBD population is exiguous.

Understanding the pathophysiology of gut-muscle axis is key to developing translational research in this area of intense interest. Hence, we hope to encourage intervention studies exploring the impact of modulation GM on muscle function in IBD patients. 


\section{AUTHOR CONTRIBUTIONS}

OMN and RdS contributed to conception, design, drafting, and revised of the manuscript. VP and FS wrote sections of the manuscript. AT and
GV contributed to manuscript draft. FC critically reviewed the manuscript for important intellectual content, edited, revised, and provided overall supervision. All authors contributed to the article and approved the submitted version.

\section{REFERENCES}

1. Cruz-Jentoft AJ, Bahat G, Bauer J, Boirie Y, Bruyère O. Et Al; Writing Group for the European Working Group on Sarcopenia in Older People 2 (EWGSOP2), and the Extended Group for EWGSOP2. Sarcopenia: revised European consensus on definition and diagnosis. Age Ageing (2019) 48:16-31. doi: 10.1093/ageing/afy169

2. Sousa AS, Guerra RS, Fonseca I, Pichel F, Ferreira S, Amaral TF. Financial Impact of Sarcopenia on Hospitalization Costs. Eur J Clin Nutr (2016) 70:1046-51. doi: 10.1038/ejcn.2016.73

3. de Sire A, Baricich A, Renò F, Cisari C, Fusco N, Invernizzi M. Myostatin as a Potential Biomarker to Monitor Sarcopenia in Hip Fracture Patients Undergoing a Multidisciplinary Rehabilitation and Nutritional Treatment: A Preliminary Study. Aging Clin Exp Res (2020) 32:959-62. doi: 10.1007/ s40520-019-01436-8

4. Ryan E, McNicholas D, Creavin B, Kelly ME, Walsh T, Beddy D. Sarcopenia and Inflammatory Bowel Disease: A Systematic Review. Inflamm Bowel Dis (2019) 25:67-73. doi: 10.1093/ibd/izy212

5. Sokol H, Pigneur B, Watterlot L, Lakhdari O, Bermúdez-Humarán LG, Gratadoux JJ, et al. Faecalibacteriumprausnitzii is an Anti-Inflammatory Commensal Bacterium Identified by Gut Microbiota Analysis of Crohn Disease Patients. Proc Natl Acad Sci U.S.A. (2008) 105:16731-6. doi: 10.1073/pnas.0804812105

6. Zhang YZ, Li YY. Inflammatory Bowel Disease: Pathogenesis. World J Gastroenterol (2014) 20:91-9. doi: 10.3748/wjg.v20.i1.91

7. de Sire R, Talocco C, Petito V, Lopetuso LR, Graziani C, Gasbarrini A, et al. Microbiota and Inflammatory Bowel Disease: An Update. Recenti Prog Med (2018) 109:570-3. doi: 10.1701/3082.30741

8. Britton GJ, Contijoch EJ, Mogno I, Vennaro OH, Llewellyn SR, Ng R, et al. Microbiotas From Humans With Inflammatory Bowel Disease Alter the Balance of Gut Th17 and Roryt+ Regulatory T Cells and Exacerbate Colitis in Mice. Immunity (2019) 50:212-24. doi: 10.1016/j.immuni.2018.12.015

9. Lopetuso LR, Ianiro G, Allegretti JR, Bibbò S, Gasbarrini A, Scaldaferri F, et al. Fecal Transplantation for Ulcerative Colitis: Current Evidence and Future Applications. Expert Opin Biol Ther (2020) 20:343-51. doi: 10.1080/ 14712598.2020.1733964

10. Arumugam M, Raes J, Pelletier E, Le Paslier D, Yamada T, Mende DR, et al. Enterotypes of the Human Gut Microbiome. Nature (2011) 473:174-80. doi: 10.1038/nature09944

11. Kamada N, Seo SU, Chen GY, Núnez G. Role of the Gut Microbiota in Immunity and Inflammatory Disease. Nat Rev Immunol (2013) 13:321-35. doi: $10.1038 /$ nri3430

12. Sommer F, Bäckhed F. The Gut Microbiota-Masters of Host Development and Physiology. Nat Rev Microbiol (2013) 11:227-38. doi: 10.1038/nrmicro2974

13. de Sire A, de Sire R, Petito V, Masi L, Cisari C, Gasbarrini A, et al. Gut-Joint Axis: The Role of Physical Exercise on Gut Microbiota Modulation in Older People With Osteoarthritis. Nutrients (2020) 12:574. doi: 10.3390/ nu12020574

14. Walker AW, Sanderson JD, Churcher C, Parkes GC, Hudspith BN, Rayment N, et al. High-Throughput Clone Library Analysis of the Mucosa-Associated Microbiota Reveals Dysbiosis and Differences Between Inflamed and nonInflamed Regions of the Intestine in Inflammatory Bowel Disease. BMC Microbiol (2011) 11:7. doi: 10.1186/1471-2180-11-7

15. Halfvarson J, Brislawn CJ, Lamendella R, Vázquez-Baeza Y, Walters WA, Bramer LM, et al. Dynamics of the Human Gut Microbiome in Inflammatory Bowel Disease. Nat Microbiol (2017) 2:17004. doi: 10.1038/ nmicrobiol.2017.4

16. Ni J, Wu GD, Albenberg L, Tomov VT. Gut Microbiota and IBD: Causation or Correlation? Nat Rev Gastroenterol Hepatol (2017) 14:573-84. doi: $10.1038 /$ nrgastro. 2017.88 LL, et al. Nutrition and IBD: Malnutrition and/or Sarcopenia? A Practical Guide. Gastroenterol Res Pract (2017) 2017:8646495. doi: 10.1155/2017/ 8646495

18. de Sire R, Rizzatti G, Ingravalle F, Pizzoferrato M, Petito V, Lopetuso L, et al. Skeletal Muscle-Gut Axis: Emerging Mechanisms of Sarcopenia for Intestinal and Extra Intestinal Diseases. Minerva Gastroenterol Dietol (2018) 64:351-62. doi: 10.23736/S1121-421X.18.02511-4

19. Pizzoferrato M, de Sire R, Ingravalle F, Mentella MC, Petito V, Martone AM, et al. Characterization of Sarcopenia in an IBD Population Attending an Italian Gastroenterology Tertiary Center. Nutrients (2019) 11:2281. doi: 10.3390/nu11102281

20. Ticinesi A, Lauretani F, Milani C, Nouvenne A, Tana C, Del Rio D, et al. Aging Gut Microbiota at the Cross-Road Between Nutrition, Physical Frailty, and Sarcopenia: Is There a Gut-Muscle Axis? Nutrients (2017) 9:1303. doi: 10.3390/nu9121303

21. Ehlers L, Bannert K, Rohde S, Berlin P, Reiner J, Wiese M, et al. Preclinical Insights Into the Gut-Skeletal Muscle Axis in Chronic Gastrointestinal Diseases. J Cell Mol Med (2020) 24:8304-14. doi: 10.1111/jcmm.15554

22. Franceschi C, Bonafè M, Valensin S, Olivieri F, De Luca M, Ottaviani E, et al. Inflamm-Aging. An Evolutionary Perspective on Immunosenescence. Ann N Y Acad Sci (2000) 908:244-54. doi: 10.1111/j.1749-6632.2000.tb06651.x

23. Dalle S, Rossmeislova L, Koppo K. The Role of Inflammation in Age-Related Sarcopenia. Front Physiol (2017) 8:1045. doi: 10.3389/fphys.2017.01045

24. Chhetri JK, de Souto Barreto P, Fougère B, Rolland Y, Vellas B, Cesari M Chronic Inflammation and Sarcopenia: A Regenerative Cell Therapy Perspective. Exp Gerontol (2018) 103:115-23. doi: 10.1016/ j.exger.2017.12.023

25. Pedersen M, Cromwell J, Nau P. Sarcopenia Is a Predictor of Surgical Morbidity in Inflammatory Bowel Disease. Inflammation Bowel Dis (2017) 10:1867-72. doi: 10.1097/MIB.0000000000001166

26. Günther C, Martini E, Wittkopf N, Amann K, Weigmann B, Neumann H, et al. Caspase- 8 Regulates TNF- $\alpha$-Induced Epithelial Necroptosis and Terminal Ileitis. Nature (2011) 477:335-9. doi: 10.1038/nature10400

27. Leppkes M, Roulis M, Neurath MF, Kollias G, Becker C. Pleiotropic Functions of TNF- $\alpha$ in the Regulation of the Intestinal Epithelial Response to Inflammation. Int Immunol (2014) 26:509-15. doi: 10.1093/ intimm/dxu051

28. Wu XX, Huang XL, Chen RR, Li T, Ye HJ, Xie W, et al. Paeoniflorin Prevents Intestinal Barrier Disruption and Inhibits Lipopolysaccharide (LPS)Induced Inflammation in Caco-2 Cell Monolayers. Inflammation (2019) 6:2215-25. doi: 10.1007/s10753-019-01085-Z

29. Zeissig S, Bürgel N, Günzel D, Richter J, Mankertz J, Wahnschaffe U, et al. Changes in Expression and Distribution of Claudin 2, 5 and 8 Lead to Discontinuous Tight Junctions and Barrier Dysfunction in Active Crohn's Disease. Gut (2007) 1:61-72. doi: 10.1136/gut.2006.094375

30. Heller F, Florian P, Bojarski C, Richter J, Christ M, Hillenbrand B, et al Interleukin-13 Is the Key Effector Th2 Cytokine in Ulcerative Colitis That Affects Epithelial Tight Junctions, Apoptosis, and Cell Restitution. Gastroenterology (2005) 2:550-64. doi: 10.1016/j.gastro.2005.05.002

31. Ghosh SS, Wang J, Yannie PJ, Ghosh S. Intestinal Barrier Dysfunctionand Disease Development. J Endocr. Soc (2020) 20:4:bvz039. doi: 10.1210/jendso/ bvz039

32. Schaap LA, Pluijm SM, Deeg DJ, Harris TB, Kritchevsky SB, Newman AB, et al. Higher Inflammatory Marker Levels in Older Persons: Associations With 5-Year Change in Muscle Mass and Muscle Strength. J Gerontol. A. Biol Sci Med Sci (2009) 64:1183-9. doi: 10.1093/gerona/glp097

33. Cohen S, Nathan JA, Goldberg AL. Muscle Wasting in Disease: Molecular Mechanisms and Promising Therapies. Nat Rev Drug Discovery (2015) 14:58-74. doi: $10.1038 / \mathrm{nrd} 4467$ 
34. Atreya R, Mudter J, Finotto S, Müllberg J, Jostock T, Wirtz S, et al. Blockade of Interleukin 6 Trans Signaling Suppresses T-Cell Resistance Against Apoptosis in Chronic Intestinal Inflammation: Evidence in Crohn Disease and Experimental Colitis In Vivo. Nat Med (2000) 6:583-8. doi: 10.1038/ 75068

35. Kai Y, Takahashi I, Ishikawa H, Hiroi T, Mizushima T, Matsuda C, et al. Colitis in Mice Lacking the Common Cytokine Receptor Gamma Chain Is Mediated by IL-6-Producing CD4+ T Cells. Gastroenterology (2005) 128:922-34. doi: 10.1053/j.gastro.2005.01.013

36. Steinbacher P, Eckl P. Impact of Oxidative Stress on Exercising Skeletal Muscle. Biomolecules (2015) 5:356-77. doi: 10.3390/biom5020356

37. Bian AL, Hu HY, Rong YD, Wang J, Wang JX, Zhou XZ. A Study on Relationship Between Elderly Sarcopenia and Inflammatory Factors IL-6 and TNF- $\alpha$. Eur J Med Res (2017) 22:25. doi: 10.1186/s40001-017-0266-9

38. Onesti JK, Guttridge DC. Inflammation Based Regulation of Cancer Cachexia. Biomed Res Int (2014) 2014:168407. doi: 10.1155/2014/168407

39. Shivaji UN, Nardone OM, Cannatelli R, Smith SC, Ghosh S, Iacucci M. Small Molecule Oral Targeted Therapies in Ulcerative Colitis. Lancet Gastroenterol Hepatol (2020) 5:850-61. doi: 10.1016/S2468-1253(19)30414-5

40. Peake JM, Della Gatta P, Suzuki K, Nieman DC. Cytokine Expression and Secretion by Skeletal Muscle Cells: Regulatory Mechanisms and Exercise Effects. Exerc Immunol Rev (2015) 21:8-25.

41. VanderVeen BN, Fix DK, Carson JA. Disrupted Skeletal Muscle Mitochondrial Dynamics, Mitophagy, and Biogenesis During Cancer Cachexia: A Role for Inflammation. Oxid Med Cell Longev (2017) 2017:3292087. doi: 10.1155/2017/3292087

42. Supinski GS, Callahan LA. Free Radical-Mediated Skeletal Muscle Dysfunction in Inflammatory Conditions. J Appl Physiol (2007) 5:205663. doi: 10.1152/japplphysiol.01138.2006

43. Alula KM, Jackson DN, Smith AD, Kim DS, Turner K, Odstrcil E, et al. Targeting Mitochondrial Damage as a Therapeutic for Ileal Crohn's Disease. Cells (2021) 10:1349. doi: 10.3390/cells10061349

44. Jackson DN, Panopoulos M, Neumann WL, Turner K, Cantarel BL, Thompson-Snipes L, et al. Mitochondrial Dysfunction During Loss of Prohibitin 1 Triggers Paneth Cell Defects and Ileitis. Gut (2020) 69:192838. doi: 10.1136/gutjnl-2019-319523

45. Parada Venegas D, de la Fuente MK, Landskron G, González MJ, Quera R, Dijkstra G, et al. Short Chain Fatty Acids (SCFAs)-Mediated Gut Epithelial and Immune Regulation and Its Relevance for Inflammatory Bowel Diseases. Front Immunol (2019) 10:277. doi: 10.3389/fimmu.2019.00277

46. Qin J, Li R, Raes J, Arumugam M, Burgdorf KS, Manichanh C, et al. A Human Gut Microbial Gene Catalogue Established by Metagenomic Sequencing. Nature (2010) 464:59-65. doi: 10.1038/nature08821

47. Huttenhower C, Gevers D, Knight R, Abubucker S, Badger JH, Chinwalla AT. Human Microbiome Project Consortium. Structure, Function and Diversity of the Healthy Human Microbiome. Nature (2012) 486:207-14. doi: 10.1038/nature11234

48. Sender R, Fuchs S, Milo R. Revised Estimates for the Number of Human and Bacteria Cells in the Body. PLoS. Biol (2016) 14:e1002533. doi: 10.1371/ journal.pbio. 1002533

49. Lee M, Chang EB. Inflammatory Bowel Diseases (IBD) and the MicrobiomeSearching the Crime Scene for Clues. Gastroenterology (2021) 160:524-37. doi: 10.1053/j.gastro.2020.09.056

50. Graziani C, Talocco C, de Sire R, Petito V, Lopetuso LR, Gervasoni J, et al. Intestinal Permeability in Physiological and Pathological Conditions: Major Determinants and Assessment Modalities. Eur Rev Med Pharmacol Sci (2019) 23:795-810. doi: 10.26355/eurrev_201901_16894

51. Franceschi C, Garagnani P, Parini P, Giuliani C, Santoro A. Inflammaging: A New Immune-Metabolic Viewpoint for Age-Related Diseases. Nat Rev Endocrinol (2018) 14:576-90. doi: 10.1038/s41574-018-0059-4

52. Schultsz C, Van Den Berg FM, Ten Kate W, Tytgat W, Dankert W. The Intestinal Mucus Layer From Patients With Inflammatory Bowel Disease Harbors High Numbers of Bacteria Compared With Controls. Gastroenterology (1999) 117:1089-97. doi: 10.1016/S0016-5085(99)70393-8

53. Manichanh C, Rigottier-Gois L, Bonnaud E, Gloux K, Pelletier E, Frangeul L, et al. Reduced Diversity of Faecal Microbiota in Crohn's Disease Revealed by a Metagenomic Approach. Gut (2006) 55:205-11. doi: 10.1136/ gut.2005.073817
54. Qin J, Li R, Raes J, Arumugam M, Burgdorf KS, Manichanh C, et al. A Human Gut Microbial Gene Catalogue Established by Metagenomic Sequencing. Nature (2010) 464:59-65. doi: 10.1038/nature08821

55. Lloyd-Price J, Arze C, Ananthakrishnan AN, Schirmer M, Avila-Pacheco J, Poon TW, et al. Multi-Omics of the Gut Microbial Ecosystem in Inflammatory Bowel Diseases. Nature (2019) 569:655. doi: 10.1038/s41586-019-1237-9

56. Joossens M, Huys G, Cnockaert M, De Preter V, Verbeke K, Rutgeerts P, et al. Dysbiosis of the Faecal Microbiota in Patients With Crohn's Disease and Their Unaffected Relatives. Gut (2011) 60:631-7. doi: 10.1136/gut.2010.223263

57. Walsh ME, Bhattacharya A, Sataranatarajan K, Qaisar R, Sloane L, Rahman $\mathrm{MM}$, et al. The Histone Deacetylase Inhibitor Butyrate Improves Metabolism and Reduces Muscle Atrophy During Aging. Aging Cell (2015) 14:957-70. doi: 10.1111/acel.12387

58. Dukes A, Davis C, El Refaey M, Upadhyay S, Mork S, Arounleut P, et al. The Aromatic Amino Acid Tryptophan Stimulates Skeletal Muscle IGF1/p70s6k/ mTor Signaling In Vivo and the Expression of Myogenic Genes In Vitro. Nutrition (2015) 31:1018-24. doi: 10.1016/j.nut.2015.02.011

59. Kobayashi Y, Hara N, Sugimoto R, Mifuji-Moroka R, Tanaka H, Eguchi A, et al. The Associations Between Circulating Bile Acids and the Muscle Volume in Patients With Non-Alcoholic Fatty Liver Disease (NAFLD). Intern Med (2017) 56:755-62. doi: 10.2169/internalmedicine.56.7796

60. LeBlanc JG, Laiño JE, del Valle MJ, Vannini V, van Sinderen D, Taranto MP, et al. B-Group Vitamin Production by Lactic Acid Bacteria-Current Knowledge and Potential Applications. J Appl Microbiol (2011) 111:1297309. doi: 10.1111/j.1365-2672.2011.05157.x

61. Ryu D, Mouchiroud L, Andreux PA, Katsyuba E, Moullan N, Nicolet-DitFélix AA, et al. Urolithin A Induces Mitophagy and Prolongs Lifespan in C. elegans and increases muscle function in rodents. Nat Med (2016) 22:87988. doi: $10.1038 / \mathrm{nm} .4132$

62. Siddharth J, Chakrabarti A, Pannérec A, Karaz S, Morin-Rivron D, Masoodi $\mathrm{M}$, et al. Aging and Sarcopenia Associate With Specific Interactions Between Gut Microbes, Serum Biomarkers and Host Physiology in Rats. Aging (Albany NY) (2017) 9:1698-720. doi: 10.18632/aging.101262

63. Wu C, Kim DH, Xue QL, Lee DSH, Varadhan R, Odden MC. Association of Frailty With Recovery From Disability Among Community-Dwelling Older Adults: Results From Two Large U.S. Cohorts. J Gerontol. A. Biol Sci Med Sci (2019) 74:575-81. doi: 10.1093/gerona/gly080

64. Hatter JA, Kouche YM, Melchor SJ, Ng K, Bouley DM, Boothroyd JC, et al. Toxoplasma Gondii Infection Triggers Chronic Cachexia and Sustained Commensal Dysbiosis in Mice. PLoS. One (2018) 13:e0204895. doi: 10.1371/ journal.pone.0204895

65. Ni Lochlainn M, Bowyer RCE, Steves CJ. Dietary Protein and Muscle in Aging People: The Potential Role of the Gut Microbiome. Nutrients (2018) 10:929. doi: 10.3390/nu10070929

66. Lin R, Liu W, Piao M, Zhu H. A Review of the Relationship Between the Gut Microbiota and Amino Acid Metabolism. Amino. Acids (2017) 49:2083-90. doi: 10.1007/s00726-017-2493-3

67. Dhaliwal A, Quinlan JI, Overthrow K, Greig C, Lord JM, Armstrong MJ, et al. Sarcopenia in InflammatoryBowelDisease: A Narrative Overview. Nutrients (2021) 13:656. doi: 10.3390/nu13020656

68. Picca A, Ponziani FR, Calvani R, Marini F, Biancolillo A, Coelho-Junior HJ, et al. Gut Microbial, Inflammatory and Metabolic Signatures in Older People With Physical Frailty and Sarcopenia: Results From the BIOSPHERE Study. Nutrients (2019) 12:65. doi: 10.3390/nu12010065

69. Clarke SF, Murphy EF, O’Sullivan O, Lucey AJ, Humphreys M, Hogan A, et al. Exercise and Associated Dietary Extremes Impact on Gut Microbial Diversity. Gut (2014) 63:1913-20. doi: 10.1136/gutjnl-2013-306541

70. Bressa C, Bailén-Andrino M, Pérez-Santiago J, González-Soltero R, Pérez M, Montalvo-Lominchar MG, et al. Differences in Gut Microbiota Profile Between Women With Active Lifestyle and Sedentary Women. PLoS. One (2017) 12:e0171352. doi: 10.1371/journal.pone.0171352

71. Barton W, Penney NC, Cronin O, Garcia-Perez I, Molloy MG, Holmes E, et al. The Microbiome of Professional Athletes Differs From That of More Sedentary Subjects in Composition and Particularly at the Functional Metabolic Level. Gut (2018) 67:625-33. doi: 10.1136/gutjnl-2016-313627

72. Petersen LM, Bautista EJ, Nguyen H, Hanson BM, Chen L, Lek SH, et al. Community Characteristics of the Gut Microbiomes of Competitive Cyclists. Microbiome (2017) 5:98. doi: 10.1186/s40168-017-0320-4 
73. Ticinesi A, Nouvenne A, Cerundolo N, Catania P, Prati B, Tana C, et al. Gut Microbiota, Muscle Mass and Function in Aging: A Focus on Physical Frailty and Sarcopenia. Nutrients (2019) 11:1633. doi: 10.3390/nu11071633

74. Bjørkhaug ST, Aanes H, Neupane SP, Bramness JG, Malvik S, Henriksen C, et al. Characterization of Gut Microbiota Composition and Functions in Patients With Chronic Alcohol Overconsumption. Gut Microbes (2019) 10:663-75. doi: 10.1080/19490976.2019.1580097

75. Morita E, Yokohama H, Imai D, Takeda R, Ota A, Kawai E, et al. Aerobic Exercise Training With Brisk Walking Increases Intestinal Bacteroides in Elderly Women. Nutrients (2019) 11:868. doi: 10.3390/nu11040868

76. Fielding RA, Reeves AR, Jasuja R, Liu C, Barrett BB, Lustgarten MS. Muscle Strength Is Increased in Mice That Are Colonized With Microbiota From High-Functioning Older Adults. Exp Gerontol (2019) 127:110722. doi: 10.1016/j.exger.2019.110722

77. Varian BJ, Gourishetti S, Poutahidis T, Lakritz JR, Levkovich T, Kwok C, et al. Beneficial Bacteria Inhibit Cachexia. Oncotarget (2016) 7:11803-16. doi: 10.18632/oncotarget.7730

78. Buigues C, Fernández-Garrido J, Pruimboom L, Hoogland AJ, NavarroMartínez R, Martínez-Martínez M, et al. Effect of a Prebiotic Formulation on Frailty Syndrome: A Randomized, Double-Blind Clinical Trial. Int J Mol Sci (2016) 17:932. doi: 10.3390/ijms17060932

79. Munukka E, Rintala A, Toivonen R, Nylund M, Yang B, Takanen A, et al. Faecalibacteriumprausnitzii Treatment Improves Hepatic Health and Reduces Adipose Tissue Inflammation in High-Fat Fed Mice. ISME J (2017) 11:1667-79. doi: 10.1038/ismej.2017.24

80. Shanahan F, van Sinderen D, O’Toole PW, Stanton C. Feeding the Microbiota: Transducer of Nutrient Signals for the Host. Gut (2017) 9:1709-17. doi: 10.1136/gutjnl-2017-313872

81. Beaudart C, Sanchez-Rodriguez D, Locquet M, Reginster JY, Lengelé L, Bruyère O. Malnutrition as a Strong Predictor of the Onset of Sarcopenia. Nutrients (2019) 11:2883. doi: 10.3390/nu11122883

82. Velázquez Alva Mdel C, Irigoyen Camacho ME, Delgadillo Velázquez J, Lazarevich I. The Relationship Between Sarcopenia, Undernutrition, Physical Mobility and Basic Activities of Daily Living in a Group of Elderly Women of Mexico City. Nutr Hosp (2013) 28:514-21. doi: 10.3305/nh.2013.28.2.6180

83. Valentini L, Schaper L, Buning C, Hengstermann S, Koernicke T, Tillinger W, et al. Malnutrition and Impaired Muscle Strength in Patients With Crohn's Disease and Ulcerative Colitis in Remission. Nutrition (2008) 24:694-702. doi: 10.1016/j.nut.2008.03.018

84. Hartman C, Eliakim R, Shamir R. Nutritional Status and Nutritional Therapy in Inflammatory Bowel Diseases. World J Gastroenterol (2009) 15:2570-8. doi: 10.3748/wjg.15.2570

85. Rocha R, Santana GO, Almeida N, Lyra AC. Analysis of Fat and Muscle Mass in Patients With Inflammatory Bowel Disease During Remission and Active Phase. Br J Nutr (2009) 101:676-9. doi: 10.1017/S0007114508032224

86. Adams DW, Gurwara S, Silver HJ, Horst SN, Beaulieu DB, Schwartz DA, et al. Sarcopenia Is Common in Overweight Patients With Inflammatory Bowel Disease and May Predict Need for Surgery. Inflamm Bowel Dis (2017) 23:1182-6. doi: 10.1097/MIB.0000000000001128

87. Ünal NG, Oruç N, Tomey O, ÖmerÖzütemiz A. Malnutrition and Sarcopenia are Prevalent Among Inflammatory Bowel Disease Patients With Clinical Remission. Eur J Gastroenterol Hepatol (2021) 1:18. doi: 10.1097/MEG.0000000000002044

88. Casanova MJ, Chaparro M, Molina B, Merino O, Batanero R, DueñasSadornil C, et al. Prevalence of Malnutrition and Nutritional Characteristics of Patients With Inflammatory Bowel Disease. J CrohnsColitis (2017) 11:1430-9. doi: 10.1093/ecco-jcc/jjx102

89. Cioffi I, Imperatore N, Di Vincenzo O, Pagano MC, Santarpia L, Pellegrini L, et al. Evaluation of Nutritional Adequacy in Adult Patients With Crohn's Disease: A Cross-Sectional Study. Eur J Nutr (2020) 59:3647-58. doi: 10.1007/s00394-020-02198-0

90. Milani C, Ferrario C, Turroni F, Duranti S, Mangifesta M, van Sinderen D, et al. The Human Gut Microbiota and its Interactive Connections to Diet. J Hum Nutr Diet (2016) 5:539-46. doi: 10.1111/jhn.12371

91. Rinninella E, Raoul P, Cintoni M, Franceschi F, Gasbarrini A, et al. What Is the Healthy Gut Microbiota Composition? A Changing Ecosystem Across Age, Environment, Diet, and Diseases. Microorganisms (2019) 1:14. doi: 10.3390/microorganisms7010014
92. Gentile CL, Weir TL. The Gut Microbiota at the Intersection of Diet and Human Health. Science (2018) 6416:776-80. doi: 10.1126/science.aau5812

93. Murphy EA, Velazquez KT, Herbert KM. Influence of High-Fat Diet on Gut Microbiota: A Driving Force for Chronic Disease Risk. Curr Opin Clin Nutr Metab Care (2015) 5:515-20. doi: 10.1097/MCO.0000000000000209

94. Monira S, Nakamura S, Gotoh K, Izutsu K, Watanabe H, Alam NH, et al. Gut Microbiota of Healthy and Malnourished Children in Bangladesh. Front Microbiol (2011) 2:228. doi: 10.3389/fmicb.2011.00228

95. Genton L, Cani PD, Schrenzel J. Alterations of Gut Barrier and Gut Microbiota in Food Restriction, Food Deprivation and Protein-Energy Wasting. Clin Nutr (2015) 3:341-9. doi: 10.1016/j.clnu.2014.10.003

96. Rondanelli M, Klersy C, Terracol G, Talluri J, Maugeri R, Guido D, et al. Whey Protein, Amino Acids, and Vitamin D Supplementation With Physical Activity Increases Fat-Free Mass and Strength, Functionality, and Quality of Life and Decreases Inflammation in Sarcopenic Elderly. Am J Clin Nutr (2016) 103:830-40. doi: 10.3945/ajcn.115.113357

97. Courel-Ibáñez J, Vetrovsky T, Dadova K, Pallarés JG, Steffl M. Health Benefits of $\beta$-Hydroxy- $\beta$-Methylbutyrate (HMB) Supplementation in Addition to PhysicalExercise in OlderAdults: A Systematic Review With Meta-Analysis. Nutrients (2019) 9:2082. doi: 10.3390/nu11092082

98. Deutz NE, Bauer JM, Barazzoni R, Biolo G, Boirie Y, Bosy-Westphal A, et al. Protein Intake and Exercise for Optimal Muscle Function With Aging: Recommendations From the ESPEN Expert Group. Clin Nutr (2014) 33:929-36. doi: 10.1016/j.clnu.2014.04.007

99. Forbes A, Escher J, Hébuterne X, Kłęk S, Krznaric Z, Schneider S, et al. ESPEN Guideline: Clinical Nutrition in Inflammatory Bowel Disease. Clin Nutr (2017) 36:321-47. doi: 10.1016/j.clnu.2016.12.027

100. Del Pinto R, Pietropaoli D, Chandar AK, Ferri C, Cominelli F. Association Between Inflammatory Bowel Disease and Vitamin D Deficiency: A Systematic Review and Meta-Analysis. Inflamm BowelDis (2015) 21:270817. doi: 10.1097/MIB.0000000000000546

101. Garcia M, Seelaender M, Sotiropoulos A, Coletti D, Lancha AH Jr., et al. Muscle Recovery, Sarcopenia, Cachexia, and Muscle Atrophy. Nutrition (2019) 60:66-9. doi: 10.1016/j.nut.2018.09.031

102. Molina P, Carrero JJ, Bover J, Chauveau P, Mazzaferro S, Torres PU. European Renal Nutrition (ERN) and Chronic Kidney Disease-Mineral and Bone Disorder (CKD-MBD) Working Groups of the European Renal Association-European Dialysis Transplant Association (ERA-EDTA). Vitamin D, a Modulator of Musculoskeletal Health in Chronic Kidney Disease. J Cachexia Sarcopenia Muscle (2017) 8:686-701. doi: 10.1002/jcsm.12218

103. Ceglia L, da Silva Morais M, Park LK, Morris E, Harris SS, Bischoff-Ferrari HA, et al. Multi-Step Immunofluorescent Analysis of Vitamin D Receptor Loci and Myosin Heavy Chain Isoforms in Human Skeletal Muscle. J Mol Histol (2010) 41:137-42. doi: 10.1007/s10735-010-9270-x

104. Ticinesi A, Meschi T, Lauretani F, Felis G, Franchi F, Pedrolli C, et al. Nutrition and Inflammation in Older Individuals: Focus on Vitamin D, N-3 Polyunsaturated Fatty Acids and Whey Proteins. Nutrients (2016) 8:186. doi: 10.3390/nu8040186

105. Oh SY, Cho KA, Kang JL, Kim KH, Woo SY. Comparison of Experimental Mouse Models of Inflammatory Bowel Disease. Int J Mol Med (2014) 33:33340. doi: 10.3892/ijmm.2013.1569

106. Puleo F, Meirelles K, Navaratnarajah M, Fitzpatrick L, Shumate ML, Cooney RN, et al. Skeletal Muscle Catabolism in Trinitrobenzene Sulfonic AcidInduced Murine Colitis. Metabolism (2010) 59:1680-90. doi: 10.1016/ j.metabol.2010.03.021

107. de Sire R, Petito V, Graziani C, Scannone D, Lopetuso LR, Pizzoferrato M, et al. Molecular Pathways of Sarcopenia in DSS Acute Model of Murine Colitis. Dig. Liv. Dis (2019) 51:71-258. doi: 10.1016/S1590-8658(19)30153-7

108. Kishimoto Y, Zhu W, Hosoda W, Sen JM, Mattson MP. Chronic Mild Gut Inflammation Accelerates Brain Neuropathology and Motor Dysfunction in $\alpha$-Synuclein Mutant Mice. Neuromolecular Med (2019) 3:239-49. doi: 10.1007/s12017-019-08539-5

109. Saul D, Kosinsky RL. Dextran Sodium Sulfate-Induced Colitis as a Model for Sarcopenia in Mice. Inflamm Bowel. Dis (2020) 26:56-65. doi: 10.1093/ibd/izz127

110. Zhang S, Fang J, Liu Z, Hou P, Cao L, Zhang Y, et al. Inflammatory Cytokines-Stimulated Human Muscle Stem Cells Ameliorate Ulcerative Colitis via the IDO-TSG6 Axis. Stem Cell Res Ther (2021) 1:50. doi: $10.1186 /$ s13287-020-02118-3 
111. Grillot J, D’Engremont C, Parmentier AL, Lakkis Z, Piton G, Cazaux D, et al. Sarcopenia and Visceral Obesity Assessed by Computed Tomography Are Associated With Adverse Outcomes in Patients With Crohn's Disease. Clin Nutr (2020) 39:3024-30. doi: 10.1016/j.clnu.2020.01.001

112. Bamba S, Inatomi O, Takahashi $\mathrm{K}$, Morita $\mathrm{Y}$, Imai $\mathrm{T}$, Ohno $\mathrm{M}$, et al. Assessment of Body Composition From CT Images at the Level of the Third Lumbar Vertebra in Inflammatory Bowel Disease. Inflamm Bowel Dis (2020) 11:25. doi: 10.1093/ibd/izaa306

113. Subramaniam K, Fallon K, Ruut T, Lane D, McKay R, Shadbolt B, et al. Infliximab Reverses Inflammatory Muscle Wasting (Sarcopenia) in Crohn's Disease. Aliment. Pharmacol Ther (2015) 41:419-28. doi: 10.1111/apt.13058

114. Csontos ÁA, Molnár A, Piri Z, Katona B, Dakó S, Pálfi E, et al. The Effect of Anti-TNF $\alpha$ Induction Therapy on the Nutritional Status and Dietary Intake in Inflammatory Bowel Disease. J Gastrointestin. Liver Dis (2016) 25:49-56. doi: $10.15403 /$ jgld.2014.1121.251
115. Theou O, Jayanama K, Fernández-Garrido J, Buigues C, Pruimboom L, Hoogland AJ, et al. Can a Prebiotic Formulation Reduce Frailty Levels in Older People? J Frailty Aging (2019) 8:48-52. doi: 10.14283/jfa.2018.39

Conflict of Interest: The authors declare that the research was conducted in the absence of any commercial or financial relationships that could be construed as a potential conflict of interest.

Copyright (C) 2021 Nardone, de Sire, Petito, Testa, Villani, Scaldaferri and Castiglione. This is an open-access article distributed under the terms of the Creative Commons Attribution License (CC BY). The use, distribution or reproduction in other forums is permitted, provided the original author(s) and the copyright owner(s) are credited and that the original publication in this journal is cited, in accordance with accepted academic practice. No use, distribution or reproduction is permitted which does not comply with these terms. 